\title{
Does everyone think the ability to do otherwise is necessary for free will and moral responsibility? Simon Kittle
}

Christopher Franklin (2014) has argued that everyone thinks the ability to do otherwise is relevant to free will and moral responsibility. In today's climes this is surprising. Since Peter Strawson's 'Freedom and Resentment' (1962) many writers have downplayed, if not outright rejected, any control condition on moral responsibility. And since Harry Frankfurt's 'Alternate Possibilities and Moral Responsibility' (1969) many have thought that even if control is important for moral responsibility it does not involve the ability to do otherwise. Franklin argues that this is mistaken: even those who explicitly say they have abandoned the ability to do otherwise condition do in fact adhere to such a condition. Call this the universality claim.

To make the universality claim plausible Franklin points out that there are in fact many different kinds of ability. It is therefore a mistake to think that there is one thing - the ability to do otherwise - which either is or is not needed for free will and moral responsibility. Given that there are different kinds of ability, there are lots of different ways an agent might be able to do otherwise. Thus the question we should be asking is this: which ability to do otherwise is needed for free will and moral responsibility? Franklin goes on to suggest that the way to settle this question will inevitably involve appeals to moral responsibility, such that we cannot in fact settle the question about ability to do otherwise until we understand the nature of moral responsibility. Call this the primacy of moral responsibility claim, or primacy for short. In this paper I will argue against both conclusions.

Franklin begins by telling us what the term 'ability' means. He gives us the following schema: 
POSTPRINT. Published version: https://link.springer.com/article/10.1007/s11406-018-0044-0

The proposition 'The agent has the ability to $\mathrm{X}$ ' means 'The agent's $\mathrm{X}$-ing is compossible with facts F' (Franklin 2014: 3).1

To attribute an ability is, therefore, first and foremost to make a modal claim: it is to say that something is possible. More precisely, it is to say that something - an action - is compossible with some set of facts. Franklin says that ability is a "relative" notion because we can alter the set of facts that we are affirming the action is compossible with. The set of facts, F, is determined by context and the intentions of the speaker, Franklin says (2014: 3). And for each different set of facts, there is a corresponding notion of ability. Franklin cites David Lewis approvingly in this respect:

To say that something can happen means that its happening is compossible with certain facts. Which facts? That is determined, but sometimes not determined well enough, by context.... It is likewise possible to equivocate about whether it is possible for me to [X], or whether I am able to, or whether I have the ability or capacity or power or potentiality to. Our many words for much the same thing are little help since they do not seem to correspond to different fixed delineations of the relevant facts (Lewis 1976: 150as cited in Franklin, p. 3).

As we vary the set of facts we get a different notion of ability, and so we have a different sense in which the agent might be able to do otherwise. Franklin contends that when people deny that the ability to do otherwise is necessary for free will and moral responsibility, what they are doing is denying that one particular conception of the ability to do otherwise is necessary for free will and moral responsibility. Moreover, Franklin contends that such theorists typically employ a different notion of ability in their positive accounts, such that although they deny that the ability to do otherwise is needed, they do in the end affirm that some ability to do otherwise is needed for free will and moral responsibility. Franklin attempts to make the universality claim plausible by demonstrating the point with John Martin Fischer's account of free will and moral responsibility. Fischer is perhaps the best known of those who deny that the ability to do otherwise is necessary for free will, so Franklin thinks it reasonable to say that if he shows how Fischer does in fact rely on some notion of the ability to do otherwise, then he will have gone some way to making universality plausible.

${ }^{1}$ I will assume here that Franklin means the proposition expressed by the sentences he names in the passage cited. 
POSTPRINT. Published version: https://link.springer.com/article/10.1007/s11406-018-0044-0

Fischer's position is known as semi-compatibilism and is characterised by his accepting that the Frankfurt-style cases show that the ability to do otherwise is not required for moral responsibility. Thus, Fischer is a compatibilist about moral responsibility and causal determinism, while remaining officially agnostic about whether the ability to do otherwise is compatible with determinism.

Franklin thinks that once we recognise that there are many different kinds of ability it will be clear that Fischer is only denying one kind of ability is necessary for free will. In particular, Fischer's denial is based on a "strong" notion of ability which Franklin characterises as follows:

$\mathrm{S}$ has the strong ability at $\mathrm{t}$ to $\mathrm{X}$ in possible world $\mathrm{W}$ if and only if there is a possible world $\mathrm{W}^{*}$ in which S X-s and everything that does not depend on S's X-ing is the same in $\mathrm{W}^{*}$ as $\mathrm{W}$ (Franklin 2014: 7).

Franklin's point is that although Fischer thinks that this kind of ability is not relevant to free will and moral responsibility, still, Fischer thinks that there are other kinds of ability which are relevant. Fischer's account of moral responsibility requires (among other things) that the agent be reasons-responsive. Reasons-responsiveness is a matter of the agent's responding to appropriate reasons (in the right way) under various circumstances. And Fischer says that an agent is morally responsible for some piece of behaviour only if it issues from a mechanism which is reasons-responsive in this way. The notion of a reasons-responsive mechanism is dispositional: an agent possesses a mechanism in virtue of what would happen under different circumstances. Franklin therefore suggests that the agent's responsibility depends "on the abilities or dispositions of the mechanism" such that "the agent is responsible only if their mechanism was able to have responded in a different way when presented with a sufficient reason to act differently" (Franklin 2014: 6).

But if, Franklins suggests, the agent's mechanism is able to do otherwise then it seems that the agent herself is able to do otherwise. Franklin points out everyone except those who endorse a theory of irreducible agent-causation will at some point bring the agent into the picture by way of some property of some part of the agent. With Fischer's account this happens at the level of mechanisms: "agents make choices, act, and are morally responsible in virtue of the activity of their mechanisms" (Franklin 2014: 6- 
POSTPRINT. Published version: https://link.springer.com/article/10.1007/s11406-018-0044-0

7). Thus, at the core of Fischer's account of moral responsibility lies a modal property which can be characterised as an ability to do otherwise. If this construal of Fischer's account is correct it supports Franklin's contention that the central issue is not whether the ability to do otherwise is necessary for free will; rather, the focus should be on which ability to do otherwise is necessary. Fischer's account, we now see, relies on an ability to do otherwise, it is just a different kind of ability as compared with those who explicitly advocate the need for an ability to do otherwise. Call those who explicitly endorse the need for as they would put it - the ability to do otherwise leeway theorists.

What should we say here? Is Franklin right that, in the end, everyone thinks that some kind of ability to do otherwise is necessary for free will and moral responsibility, it's just that people differ over which kind of ability to do otherwise? There are, I think, reasons to resist this move. I want to suggest that there is a distinction between leeway theorists and non-leeway theorists that is typically captured with the thought that the former but not the later require the ability to do otherwise.

The disagreement, I take it, is roughly as follows. Leeway theorists think that for an agent to have free will (and thus to be morally responsible) an agent needs a distinctive kind of access to alternative possibilities. The ability that leeway theorists have in mind provides this access. And the access in question is such that the agent herself is able to realise the alternative by acting. This much appears to be held in common by all leeway theorists. Consider, for example, on the compatibilist side, Keith Lehrer's analysis of 'could have done otherwise':

(Lehrer CDO) 'S could (at $\mathrm{t}_{\mathrm{i}}$ ) have done $\mathrm{A}$ at $\mathrm{t}_{\mathrm{n}}$ ' is true in the actual world $\mathrm{W}$ if and only if there is a possible world $\mathrm{w}$ having the same laws as $\mathrm{W}$ and minimally different from $\mathrm{W}$ so that ' $\mathrm{S}$ does $\mathrm{A}$ at $\mathrm{t}_{\mathrm{n}}$ ' is true in $w$ in such a way that any advantage $S$ has in $w$ for doing $A$ at $t_{n}$ which he lacks in $W$ is admissible for $S$ from $W$ and $t_{n}$ is past (Lehrer 1976: 256).

Lehrer says that an agent has the relevant kind of ability if there is a possible world where they perform the action without the help of any inadmissible advantages. An advantage is anything that helps the agent perform the action, and an inadmissible advantage is one that removes the possible world from consideration. Significantly, Lehrer says that advantages are inadmissible if they do not result from 
anything the agent herself does. Thus, we see that the relevant kind of ability is tied to the agent's own actions. For example: suppose I'm at home with no way of getting to London. The possible world where I get to London in virtue of a private driver who has been paid for by an anonymous patron and told to go to visit a random house to see if the occupants need a lift to London is one where I get to London in virtue of an advantage which is very much not of my own doing: the existence of such a private driver is wholly outside my control. On the other hand, if I'm at home and have my own car parked outside, then the possible world where I use my car and drive myself to London is one in which I get to London in virtue only of advantages which I have bestowed upon myself by my own actions. Such a possible world grounds the truth of the ability statements that Lehrer takes to be relevant to free will.

So in Lehrer's account we see the thought that the ability to do otherwise is connected in a distinctive way with what an agent is able to bring about in virtue of how she acts. Similarly with Vihvelin's recent account of ability. Vihvelin says that an agent has the narrow ability to $A$ if she is such that she would $A$ in a suitable proportion of tests-cases in response to her trying to $A$ (Vihvelin 2013: 187). We do not need to go into the Vihvelin's notion of a test-case. The important thing is that the ability to $A$ is connected to what happens when the agent tries to $A$ - that is, on the plausible assumption that trying is itself an action, Vihvelin's account connects what the agent is able to do with what happens in virtue of how the agent herself acts. It should go without saying that leeway incompatibilists accept the thought laid out above.

Fischer, on the other hand, does not. As Franklin says, Fischer's account requires that the behaviour issue from a suitable reasons-responsive mechanism. And the mechanism is dispositional: whether the agent possesses the right kind of mechanism is a modal matter, and does not depend entirely on what happens in the actual sequence. This is something that Fischer is explicit about. But Fischer does not require that the agent be able to access those alternative possibilities where she acts otherwise simply by virtue of acting. Fischer accepts that it might take a (perhaps drastic) change in the surroundings for the agent to act otherwise; at the very least, the circumstances will contain different reasons. But there is no requirement that the agent be in control of those things which are otherwise different, such that the alternative is accessed in virtue of one of the agent's actions. 
So leeway compatibilists and leeway incompatibilists agree on something that Fischer does not accept. Similarly, Fischer and the leeway incompatibilists agree on something that the leeway compatibilists reject. Namely, that the kind of ability leeway theorists want requires indeterminism. Fischer concludes that "the" ability to do otherwise isn't necessary for free will while the leeway incompatibilist will either adopt a sceptical position or think determinism is false. But the point is that there is both a genuine disagreement (Fischer vs the leeway theorists) and a genuine agreement (the compatibilists vs the incompatibilists) here.

If we adopt Franklin's terminology it becomes very difficult to express either of these in terms of abilities. So while Franklin is right to point out that Fischer's account has a modal element, is there any reason for adopting Franklin's terminology? I think not. Ordinary usage supports the idea that the distinction outlined above is at least valid at the conceptual level. As we saw, Franklin says the following:

The proposition 'The agent has the ability to X' means 'The agent's X-ing is compossible with facts F' (Franklin 2014: 3).

It is not at all clear that this is correct. Certainly, the first sentence mentioned here might entail the second sentence, but the meaning of 'ability' includes more than a mere claim about compossibility. Vihvelin, who Franklin also cites in this context (it is unclear whether Franklin aims to enlist her support, or to provide a point of comparison), is very clear about this. If we say, for example, that an athlete can win the gold medal at the next Olympics, we are plausibly taking the set of facts $\mathrm{F}$ to include facts about her abilities. But "to say this is to make a claim that is weaker than the claim that she has the ability to win. The second claim entails the first claim (if she has the ability to win, then it's compossible with the facts about her abilities that she wins), but the converse entailment does not hold" (Vihvelin 2013: 7).

How do abilities differ from a mere 'can' claim, or from modal properties such as tendencies and dispositions? For one thing, they appear to require what Barbara Vetter has called a strong "modal force" or "modal strength" (Vetter 2014). That is, the modal claim being made is stronger than mere possibility (which requires only one possible world to make the statement true). To see this, consider an athlete who is very much an outside chance to win the gold medal - indeed, she's an outside chance to win any medal. 
Now consider the scenario where everyone else in the race falls ill and our outsider wins by default. Does this possible scenario where she does indeed win show that she had the ability to win? Arguably not.

Abilities appear to share this feature with some other modal properties, e.g. tendencies and dispositions. Plausibly, a person doesn't have a tendency to T unless it's quite likely (at least with respect to some domain of cases) that he T. And an object doesn't have a disposition to D unless it exhibits D in some suitable proportion of cases. But there do appear to be some differences between abilities on the one hand and properties like tendencies and dispositions on the other. Consider Sean. Sean has the tendency to sweat, even after only having walked briskly for five minutes. Does Sean, in virtue of this tendency, have the ability to sweat? Arguably not - it at least sounds like a strange thing to affirm. Or consider Darren, who has the disposition to stub his toe (he's clumsy). Does Darren have the ability to stub his toe? Well he probably does, but not in virtue of possessing the disposition to stub his toe. That is, most people can choose to stub their toe if they so desire and it is for that reason - the connection to choice and so control - that they have the ability to stub their toe. It has nothing to do with possessing the disposition to stub one's toe, as is evidenced by the fact that many will have the ability to stub their toes in this way despite not being disposed to stub them. Again, therefore, the natural way of thinking about ability is in terms of control: the agent could choose to stub his toe and then go ahead and do it.

Neither tendencies nor dispositions have this implication or connotation. Of course, we can if we like follow Franklin and stipulate a technical notion of 'ability' such that Sean's tendency to sweat and Darren's disposition to stub his toe come out as abilities. But then we will simply have to come up with a different term to identify the kind of modal property which all leeway theorists think is important.

It is of course a contentious issue how to characterise this difference between abilities and these other modal properties. It is a large part of what the leeway incompatibilists and the leeway compatibilists are disagreeing about. And on this score Fischer sides with the leeway incompatibilists. But what the leeway theorists don't disagree about is the way in which abilities relate to the agent's action such that they evidently become significant as far as control is concerned. All of this suggests that the universality claim is false. 
It is illustrative to note that the point at which the leeway incompatibilists and compatibilists disagree will typically be the point at which the latter attempt to manufacture agency out of agent involving states - the point at which (according to the incompatibilist) agency disappears. Consider, for example, Vihvelin's notion of a narrow ability. The canonical form of a narrow ability is the ability to $A$ in response to the agent's trying to $A$. Vihvelin goes on to say that an agent tries whenever an intention causes some behaviour which is directed at $A$-ing. Crucially though, the intention does not need to be actively acquired or in any way controlled. Thus, it is not clear that the agent's trying, according to Vihvelin's understanding of trying, will count as an action, and for just that reason the leeway incompatibilist will argue that her accounts fails. But still, the fact that Vihvelin employs the notion of trying - which is plausibly considered to be an action - shows that the kind of ability she thinks is needed is closely tied to agency. This, I suggest, indicates that the leeway theorists - incompatibilist and compatibilist - have a point of agreement about the modal properties in question, something which they think warrants the name 'ability.'

What I am suggesting is that there is an identifiable desideratum which both compatibilist and incompatibilist leeway theorists find attractive. Both think it will be satisfied by the ability to do otherwise which is relevant to free will. Fischer agrees with them, and sides with the incompatibilist on what it would take for that concept of ability to be fulfilled. Reflections on the Frankfurt-style cases lead Fischer to conclude that it is not, in the end, needed for moral responsibility.

Note, though, that in making this point we need not disagree with Franklin that there are different kinds of ability. The modal claim that an attribution of 'ability' makes does indeed vary in the way that Franklin suggests, it's just that this is no reason for rejecting the idea that there is anything distinctive about abilities (as compared to dispositions, etc). Indeed, I have argued elsewhere that even if we restrict our focus to intrinsic abilities, a sentence such as 'the ability to walk' is capable of picking out any from a whole spectrum of ability properties, depending on how we fill in what Franklin refers to as "facts F" (Kittle 2015). But if all of these abilities have something distinctive which makes them an ability as opposed to a disposition then it does not follow that everyone thinks the ability to do otherwise is 
POSTPRINT. Published version: https://link.springer.com/article/10.1007/s11406-018-0044-0

necessary for free will. It might be the case that the dispositional requirements of those who reject the need for abilities is not often focused upon, but an account's being dispositional does not mean it involves abilities.

If this is right, then Franklin's primacy claim will not follow unless agency itself has to be characterised by reference to moral responsibility. That is, I've argued that abilities are best thought of as modal properties which are distinctive in virtue of being importantly connected to agency: the behaviour that is affirmed as possible is said to be so because the agent can choose or try to bring it about. If these concepts - choosing, trying - can be explicated without appeal to moral responsibility, then primacy is false too. 
POSTPRINT. Published version: https://link.springer.com/article/10.1007/s11406-018-0044-0

\section{References}

Frankfurt, H.G. (1969) 'Alternate Possibilities and Moral Responsibility', in M.S. McKenna and D. Widerker (eds.) Moral Responsibility and Alternative Possibilities, 17-25.

Franklin, C.E. (2014) 'Everyone thinks that an ability to do otherwise is necessary for free will and moral responsibility', Philosophical Studies, 2014.

Kittle, Simon (2015): Abilities To Do Otherwise. In Philosophical Studies 172 (11), pp. 3017-3035. DOI: 10.1007/s11098-015-0455-8.

Lehrer, K. (1976) 'Can' in theory and practice: A possible worlds analysis', Action theory, 1976: 242-271. Lewis, D. (1976) 'The paradoxes of time travel', American Philosophical Quarterly, 13/2: 145-152.

Strawson, P.F. (1962) 'Freedom and Resentment', in G. Watson (ed.) Free Will. $2^{\text {nd }}$ edn.: Oxford University Press.

Vetter, B. (2014) 'Dispositions without Conditionals', Mind, 123/489: 129-156.

Vihvelin, K. (2013) Causes, laws, and free will: Why determinism doesn't matter . New York: Oxford University Press. 